\title{
La intervención olvidada: Washington en la rebelión delahuertista
}

Pedro Castro

UAM-IZTAPALAPA

\begin{abstract}
Este trabajo analiza las formas de intervención estadunidense y sus resultados en favor del gobierno de Obregón en su lucha contra la rebelión delahuertista de 1923-1924 y cómo fueron la venta de armamento y equipo al gobierno y el embargo total de elementos de guerra para los delahuertistas; el asedio naval contra los rebeldes en el Golfo y el libre tránsito de tropas leales por territorio de Estados Unidos.
\end{abstract}

L a rebelión delahuertista, iniciada en 1923, fue una violenta explosión resultado de la suma de desacuerdos entre las principales fuerzas políticas del país sobre la sucesión presidencial del general Álvaro Obregón. En un país exhausto por las recientes revoluciones, rebeldes y leales se enfrentaron en diversos frentes y en una lucha en que la suerte inicial favoreció a los impugnadores del gobierno constituido. Los rebeldes lograron propinarle golpes contundentes en los principios de su aventura y, por la rapidez de sus victorias y su inmediato control sobre extensos terri- torios, su triunfo parecía cuestión de breve tiempo. En sus trazos esenciales, ellos siguieron el patrón del movimiento de Agua Prieta, en que el líder supremo había tenido una experiencia directa; esperaban también una avalancha irresistible de adhesiones a lo largo y ancho del país, con una velocidad tal que el gobierno fuese incapaz de responder a este sorpresivo movimiento.

Al principio, el choque armado se planteaba en términos de lucha estrictamente nacional, ya que existía un equilibrio en cuanto a los recursos disponibles en manos de cada uno de los contendientes. Sin embargo, había 
un elemento externo que probaría ser decisivo y frente al que los rebeldes se encontraron pronto en desventaja. El gobierno de Obregón, en un esfuerzo que lo condujo al reconocimiento de su gobierno por Washington, había logrado hacerse de un activo invaluable contra sus enemigos: el apoyo de Estados Unidos. Las diversas formas de actuación de este país en contra del movimiento rebelde serían una carga intolerable para el delahuertismo que, después de la sorpresa inicial, vería menguar los espacios ganados hasta su fracaso completo.

Desde el comienzo, los rebeldes se dieron cuenta de que sus esfuerzos por atraerse al gobierno de Estados Unidos eran inútiles. Washington estaba convencido de que la pronta "restauración de la ley.y el orden en México" solamente se daría en colaboración con el gobierno constituido, y la decisión con que actuó fue una consecuencia del acomodo de los intereses públicos y privados a las realidades de la posrevolución, logrado en buena parte por los Tratados de Bucareli. En una decisión de tintes temerarios, el presidente Calvin Coolidge lo apoyó con material de guerra, aviones, créditos, privilegios de tránsito, presiones diplomáticas, movimientos de barcos en puertos rebeldes y demás. Éste sería un paquete que a la postre resultaría decisivo para la victoria de Obregón. En ella contaron, desde luego, las ventajas estratégicas del gobierno y su óptimo aprovechamiento, así como el talento militar del presidente mexicano que brilló con la ayuda foránea en su favor.

El ensayo de investigación que presentamos, fruto de mis avances en el programa tutoral de doctorado en historia de la Facultad de Filosofia y Letras, busca aportar evidencias en favor de la idea de que la asistencia de Estados Unidos fue decisiva en la victoria militar obregonista de 1924. Una aclaración previa es más que pertinente: el punto de las iniciativas norteame. ricanas durante el movimiento rebelde es escasamente tratada en la literatura mexicana más conocida sobre el tema. Trabajos "clásicos" como El último caudillo (Luis Monroy Durán), La rebelión sin cabeza (Alonso Capetillo) o iSálvese el que pueda! (Rafael Martínez Rip-Rip) casi ignoran en lo general esta parte, reflejo si se quiere del deseo explicable de sus autores de atribuir la victoria gubernamental al genio estratégico de Obregón. Libros de línea contraria como Cincuenta años de política mexicana: memorias políticas (Jorge Prieto Laurens), La revolución mexicana José C. Valadés), o Adolfo de la Huerta y los Tratados de Bucareli (Rafael Trujillo) hacen menciones diversas, aunque incompletas. Para el logro de nuestro propósito, nos basamos fundamentalmente en algunos trábajos académicos, en documentos oficiales de Estados Unidos; así como en la prensa norteamericana de la época y en los invaluables recortes conservados por la familia De la Huerta, con la que tengo una deuda que nunca acabaré de pagar.

\section{COOlidge A LA DEFENSA \\ DE LOS INTERESES NACIONALES \\ DE ESTADOS UNIDOS}

El apoyo de Estados Unidos al gobier- 
no de Álvaro Obregón, en su lucha contra los alzados, representó un momento mayor de su historia intervencionista durante la revolución mexicana. Si bien esta participación obedeció a razones de protección de la suma de intereses estadunidenses, más allá "de la reclamación de un grupo cualquiera"1 los "derechos" de los inversionistas constituían un elemento de primera clase en la concepción de los intereses nacionales. ${ }^{2} \mathrm{El}$ presidente Coolidge tenía su versión particular de "una nueva Doctrina Monroe", como la consistente en que los bienes y las personas de los ciudadanos estadunidenses, dondequiera que se encontraran, así fuera en el extranjero, formaran parte del patrimonio general de la nación y, por lo mismo, disfrutaran de la protección ilimitada de su gobierno. ${ }^{3}$ En esta línea, las actividades de Washington hacia México durante la revolución estuvieron fuertemente orientadas a restaurar las condiciones favorables para los negocios estadunidenses, particularmente los relacionados con el petróleo y las finanzas. La simbiosis entre el Departamento de Estado y un sector del capital estadunidense con inversiones en

1 "Hughes, como lo hicieron sus predecesores, consideraba la cuestión del petróleo como una parte del espectro más amplio de los intereses económicos, los principios legales y los supuestos ideológicos (de Estados Unidos)". Freeman Smith, Estados Unidos, 1973, p. 293.

2 Véase la declaración del Departamento de Estado de junio de 1921 acerca de las relaciones entre Estados Unidos y México, en RDS, 711.12/ 350a, citado por Freeman Smith, op. cit., p. 332.

3 Gill, Nuestros, 1959, p. 221; Nuechterlein, Intereses, 1975, p. 10.
México, fue un resultado de la intensa actividad política de los grandes intereses petroleros en Washington. Tal simbiosis presentaba sus propios problemas, y ponía en tensión permanente el proceso de toma de decisiones porque el gobierno de Estados Unidos debía conciliar posturas, a menudo contradictorias, como medidas a tomar y tiempos para actuar en favor de los intereses particulares. Debe recordarse que el Departamento de Estado abrazó, en lo general, el rechazo de petroleros y dueños de tierras y minas de origen estadunidense al proyecto constitucional de 1917, particularmente en el contenido del artículo 27 , al que veían como un atentado en contra de sus derechos adquiridos. Esta resistencia contra la Constitución entró en una nueva etapa después de la victoria del Movimiento de Agua Prieta, y encontró, en el "reconocimiento" al gobierno de Obregón, un instrumento particularmente útil para obtener de él concesiones capaces de anular sus odiados contenidos. Después de casi tres lustros, el gobierno de Coolidge concluyó un largo esfuerzo de acomodo de Estados Unidos, una vez que los grandes intereses norteamericanos en México vieron, en lo general, en la declaratoria de la no retroactividad del artículo 27 constitucional, presente en los acuerdos de Bucareli, el inicio de una nueva relación con el gobierno mexicano.

Los esfuerzos denodados del presidente Obregón por obtener el reconocimiento de Estados Unidos a su gobierno y atraerlo a su lado en las luchas contra sus enemigos, fueron aspectos significativos de su mandato. 
Tal meta había estado plagada de obstáculos, empezando por la intransigencia del abogado Charles Evans Hughes, secretario de Estado durante las presidencias de Harding y Coolidge; este último desde un principio se había mostrado inflexible en sus tratos con México. Las garantías verbales de que los intereses estadunidenses serían respetados, así como las contenidas en las resoluciones sucesivas de la Suprema Corte de Justicia referentes a la Texas Oil ${ }^{4}$ fueron insuficientes para aplacar su incurable desconfianza hacia el gobierno de México. Entendía que la única manera de hacer valer sus posiciones frente a México era a través de una política de no reconocimiento del gobierno, primero de De la Huerta y luego de Álvaro Obregón, hasta que se lograse un tratado previo capaz de asegurar la no retroactividad del artículo 27 constitucional. Washington propuso un proyecto de tratado de amistad y comercio al gobierno de Obregón en 1921 donde, en forma explícita, se dijo que "los Estados Unidos Mexicanos declaran que ni la Constitución de México, puesta en vigor en 1 de mayo de 1917, ni el Decreto del 6 de enero de 1915, tienen efectos retroactivos en su aplicación". ${ }^{5}$ Desde

${ }^{4}$ La Suprema Corte de Justicia de México, al fallar el caso del amparo interpuesto por la Texas Oil Company of Mexico, S. A., reconoció sin reservas que las leyes mineras prerrevolucionarias otorgaban derechos efectivos al superficiario, solamente al ejercer actos positivos de dominio. El caso de la Texas, seguido por otros cuatro para formar jurisprudencia, vino a zanjar la controversia original. Gómez Robledo, Convenios, 1938, p. 16.

${ }^{5}$ SRE, Cuestión, 1926, p. 18. luego, el gobierno mexicano había rechazado tal proyecto, porque su aceptación hubiera sido equivalente a ceder a un chantaje que lo habria dejado muy mal parado ante los ojos de muchos compatriotas. ${ }^{6}$ En los altos círculos del poder en Estados Unidos,

${ }^{6}$ Dice un Memorándum (sin destinatario) escrito por Summerlin que "el señor Pani [...] me dijo que como el general Obregón tenía el firme propósito de satisfacer las demandas justas de los gobiernos extranjeros, no quería que, ante México y el mundo, se perdiera la espontaneidad de sus actos al realizar ese propósito bajo la apariencia de una imposición extraña. 'Si así fuera, continuó el señor Pani, aparte de quebrantarse la dignidad de México y la del presidente, se debilitaría el gobierno que éste preside, como tendría que acontecerle a todo gobierno que apareciera capaz de cumplir sus deberes internacionales sólo bajo la presión de un poder extranjero'. Refiriéndose al propuesto Trato de Amistad y Comercio, el señor Pani hizo notar que consta de dos partes: la comercial y la política. Que las cláusulas que se relacionan con la primera son, en general, aceptables [...] y que las cláusulas de carácter político-relativas prìncipalmente al artículo 27 constitucional, a las reclamaciones extranjeras por daños causados por la revolución y a la cuestión religiosa-o concuerdan, en el fondo, con el programa politico que el general Obregón está desarrollando y resultan innecesarias o inconvenientes en dicho Tratado, o contravienen la Constitución Mexicana y resultan entonces inaceptables $[\ldots]$ ". "Memorándum", en ibid., pp. 31-32. En un sentido parecido se expresó públicamente el general Obregón: "El gobierno de México ha pensado que no es posible, ni conveniente, ni necesario, firmar un tratado semejante $[. .$.$] con-$ siderando que la firma de dicho tratado [...] hubiera dado al reconocimiento el carácter de condicional y hubiera lesionado gravemente la soberanía de México". Obregón, Informe, 1924, pp. 29-30. Un agudo observador de la política mexicana del momento, E. J. Dillon, calificó al tratado previo como una "Enmienda Platt" sobre México. Dillon, Mexico (s. f.), pp. 217.218. 


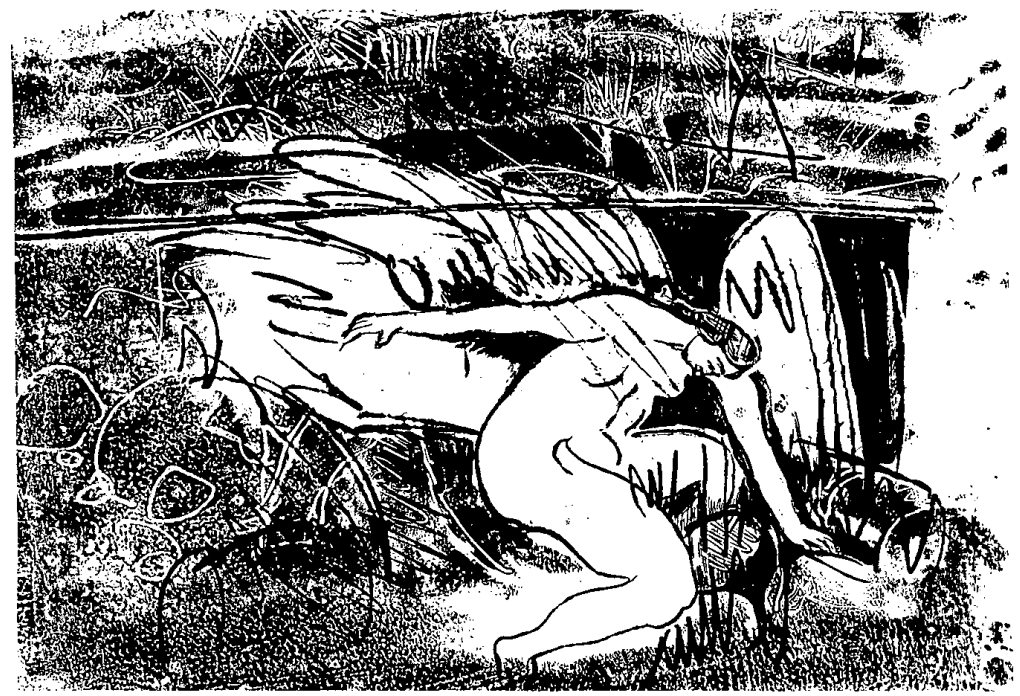

sin embargo, estaban convencidos de que, a la larga o a la corta, Obregón ten. dría que acabar asumiendo una posición "constructiva" frente a los intereses estadunidenses.

El presidente Obregón, convencido por su entonces secretario de Hacienda, Adolfo de la Huerta, de que un buen arreglo con los banqueros internacionales sobre la deuda externa de México sería decisivo para obtener el reconocimiento sin requisitos previos, apoyó en un primer momento los Acuerdos de 1922. Don Adolfo, en efecto, durante su estancia en Washington y como parte de su periplo negociador, realizó gestiones oficiosas tendientes a lograr el reconocimiento de Estados Unidos, con la seguridad de que su actuación frente al Comité In- ternacional de Banqueros había sido el primer paso en firme en tal dirección. ${ }^{7}$ A principios de 1923 la situación tomó un giro diferente. El 27 de febrero de 1923, el general Ryan, representante de la Texas Oil en México, cercano al triunvirato sonorense y al presidente Harding, comunicó a Hughes que Obregón le había mani-

7 Una vez terminadas las negociaciones con los banqueros sobre la deuda externa de México, De la Huerta fue invitado por el presidente Harding a la Casa Blanca. El 18 de julio de 1922 tuvo lugar una entrevista "cordial y animada" entre el mexicano y Harding, centrada en la cuestión del tratado previo. El presidente Har. ding habría aceptado los razonamientos de De la Huerta acerca de la inconveniencia de imponer tal tratado, y afirmado la no exigencia de nin. gún acuerdo previo. Guzmán, Memorias, 1958, p. 212. 
festado su deseo de que una comisión, formada por representantes de Estados Unidos y México, resolviera los problemas pendientes. ${ }^{8} \mathrm{El}$ gobierno norteamericano estuvo de acuerdo y las conversaciones dieron inicio el 14 de mayo de 1923 , entre los delegados Charles Beecher Warren y John Barton Payne, como representantes de Estados Unidos, y el licenciado Fernando González Roa y el señor Ramón Ross, por parte de México. Estas conversaciones concluyeron el 15 de agosto de 1923 y de ellas se desprenderían los documentos básicos para los acuerdos futuros entre México y Estados Unidos. Serían dos tratados ratificados por el Congreso de la Unión (la Convención Especial de Reclamaciones y Ia Convención General de Reclamaciones) , y otros dos "acuerdos", cuya existencia sería motivo de aguda polémica durante muchos años. ${ }^{9}$ El resultado inmediato de estas conferencias fue el logro de un modus vivendi entre Estados Unidos y México, que condujo al reconocimiento, y a la normalización de las relaciones diplomáticas entre los dos países. ${ }^{10}$ Así, tal y como lo quería el abogado Hughes, el resultado de las negociaciones quedó plasmado en instrumentos jurídicos. ${ }^{11}$

${ }^{8}$ Dulles, Ayer, 1977, p. 152.

9 Estos serian llamados los "pactos extraoficiales", asentados en las minutas o actas de las reuniones. Los obregonistas siempre los negaron. Aarón Sáenz, en Excélsior, 17 de febrero de 1958, mientras que Alessio Robles sostuvo que ellas fueron reales y que representaron una suerte de compromiso personal delgeneral Obregón. Alessio Robles, Vito, en Excélsior, 15 julio 1937.

${ }^{10}$ Freeman Smith, op. cit., p. 326.

11 En virtud de los acuerdos, México renun-
Las razones que tuvo el presidente Obregón para tomar la iniciativa de resolver los problemas de una vez por todas y de la manera en que lo hizo no son del todo claras. La hipótesis más plausible es que el presidente Obregón habría tenido la visión suficiente para darse cuenta de que 1923 iba a ser el año del rompimiento de las alianzas políticas surgidas después del Movimiento de Agua Prieta, y de que el gobierno se iba a ver en una situación apurada si no se aseguraba el apoyo de Estados Unidos para enfrentarla. La señal más visible de que una tormenta política se acercaba era que, desde principios de año, una coalición civil encabezada por el Partido Cooperatista -el más importante de la época en número y posiciones en el Congreso y en algunas gubernaturas- virtualmente había roto con Obregón. Sin embargo, es dificil de creer que el presidente hubiera previsto el estallamiento de la rebelión llamada delahuertista, con la participación de los cooperatistas, en una fecha tan lejana como los principios de ese 1923, como lo señala Enrique Arriola. ${ }^{12}$ En todo caso, queda cla-

ciaba a la retroactividad del artículo 27 , con la confirmación de la decisión de la Suprema Corte en el caso de la Texas Oil Company, y recono. cía la validez de las reclamaciones financieras estadunidenses que se remontaban a 1868. Asimismo, se comprometió a respetar los derechos sobre el subsuelo adquiridos tanto antes como después de 1917. En lo que a la deuda toca, aceptó acatar las resoluciones de una comisión especial de reclamaciones. Además González. Roa y Ross, de acuerdo con un memorándum de Obregón, prometieron que México indemnizaría a los estadunidenses por la pérdida de sus tierras. Ruiz, Gran, 1984, p. 354.

12 Enrique Arriola señala que la "fracción 
ro que el presidente mexicano llegó a la conclusión de que era preciso estar preparado para enfrentar las tormentas políticas que le esperaban, por lo que el "capítulo norteamericano" debía quedar concluido a la brevedad.

INICLATIVAS Y FRUSTRACIONES DE LOS REBELDES CON LOS ESTADUNIDENSES

La rebelión estalló en Veracruz el 5 de diciembre de 1923 , una vez que el candidato cooperatista Adolfo de la Huerta llegó a un acuerdo de lucha contra el gobierno con el general Guadalupe Sánchez, jefe de operaciones militares en ese estado. Tal levantamiento tendría como bandera declarada combatir la imposición del general Álvaro Obregón en favor del general Plutarco Elías Calles como su sucesor. El puerto de Veracruz, el principal de México por su importancia comercial y fiscal, se convirtió en la capital de los alzados y en el centro de irradiación de la rebelión hacia los estados del sureste. La flota del golfo se unió al alzamiento, y todo parecía indicar que, en muy poco tiempo, la tibera oriental del país, puerta de entrada y salida de mercaderías y del tránsito petrolero hacia Estados Unidos y Europa, sería terra franca de la nueva revolución.

obregonista sabía lo que se estaba fraguando y comenzó a adelantarse al movimiento. Meses antes del estallido de la rebelión, Obregón había iniciado la movilización de los mandos regionales asegurándose el control militar del país, dando como ejemplos San Luis Potosí y Nuevo León. La alerta de un posible levantamiento se dio, sin embargo, en las vísperas de la rebelión, no antes". Arriola, Rebeli6n, 1983, pp. 27-28.
Desde temprano surgió la necesidad de que los rebeldes entraran en tratos con el gobierno de Estados Unidos, por razones que iban desde las comerciales a las políticas, y Adolfo de la Huerta procedió de inmediato a enviar representantes a varios puntos de ese país. Con el propósito de reanudar el tráfico mercante, indispensable como fuente de ingresos para la rebelión y en general para mantener la actividad económica en la zona bajo su control, el jefe rebelde envió a Belisario A. Quiroz a Nueva York con el fin de atender los asuntos relacionados con el despacho de carga para Veracruz y otros puertos mexicanos bajo el control rebelde, ${ }^{13}$ pero fue Enrique Seldner quien finalmente se quedó con tal representación, en una función paralela a la de Alberto Masca. reñas, representante obregonista en la Agencia Financiera en esta ciudad. Mientras que Mascareñas afirmaba que el puerto de Veracruz estaba cerrado a la navegación y al comercio, Selder anunciaba que los buques de carga que viajaran de Nueva York a Veracruz sin el despacho aduanal autorizado por él tendrían que pagar cargos en este último puerto por triplicado. ${ }^{14}$ Más al sur, Teodoro Frézieres estableció en Nueva Orleans un "consulado revolucionario", también paralelo al gobiernista de Arturo M. Elías. ${ }^{15}$

Las compañías petroleras tenian prioridad en los tratos de los rebeldes con los intereses privados estaduni-

13 The Evening World [?], 15 diciembre 1923, en ARPADH.

${ }^{14}$ The Tribune, 16 diciembre 1923.

15 The New York Times, 17 diciembre 1923. 
denses. Martín Luis Guzmán, quien había sido presidente del Comité de Asuntos Exteriores de la Cámara de Diputados, llegó a Washington con el propósito declarado de abrir las oficinas delahuertistas en la capital estadunidense. ${ }^{16} \mathrm{La}$ actividad inmediata de Martín Luis fue tratar de bloquear cualquier intento del presidente Obregón para allegarse fondos a través de impuestos adelantados de las compañías petroleras estadunidenses con operaciones en México. Se dirigió a Guy Stevens, director ejecutivo de la Asociación de Productores de Petróleo en México, señalándole que "a partir de ese momento el gobierno revolucionario no reconocería los pagos adelantados que podrían ser hechos por el gobierno de Obregón a cuenta de la producción y de los impuestos por exportación. ${ }^{17}$ Por cierto, Edward L.

${ }^{16}$ En el curso de una entrevista con un reportero neoyorkino, Guzmán habló con optimismo de la próxima victoria de la causa delahuertista. Asimismo, sostuvo que "había algunos mexicanos, quienes pensaban que el general Calles podría establecer un gobierno bolchevique [...] pero son muy pocos quienes tienen esta perspectiva". Representantes posteriores de De la Huerta, como Juan Manuel Álvarez del Castillo, hablarían una y otra vez del "peligro bolchevique" representado por Calles The New York Times [?], ¿15 diciembre 1923 [?], en ARPADH.

${ }_{17}$ The New York Times, 18 diciembre 1923. A lo largo de esos dos últimos años, y cuando De la Huerta era miembro del gabinete, solicitó con frecuencia el pago adelantado de los impuestos, de acuerdo a Mr. Stevens. Declaró no tener datos a la mano para decir a cuánto ascendieron, pero sí que habían ascendido "a millones de dólares". Sólo la Pan-American Petroleum and Transport Company había dado un avance por 10 millones de pesos oro al gobierno de Obregón, por concepto de impuestos a la producción
Doheney, presidente de la Pan-American Petroleum and Transport Company y la Mexican Petroleum Company, fue un generoso contribuyente financiero a la causa de Obregón con 5000000 de dólares pagados a finales de diciembre de 1923, por concepto de "préstamo forzoso", según él mismo declaró a un comité del Senado norteamericano, argumento que no convenció a nadie. ${ }^{18}$

Doheney tenía razones poderosas para apoyar al gobierno obregonista. Las fuerzas de De la Huerta habían tomado posesión de las propiedades de la Pan-American con el propósito de asestar un "efecto sentimental" o un escarmiento para las demás compañías. ${ }^{19}$ Una vez que las zonas petroleras aledañas a Veracruz quedaran en sus manos, De la Huerta decretaría que los impuestos debían ser pagados solamente a los rebeldes. El jefe de la nueva revolución estipuló que los impuestos a la exportación de petróleo, establecidos por el decreto de junio

para 1924. The New York Times [?], 3 enero 1924, en ARPADH.

${ }^{18}$ Doheney fue investigado por cargos de prácticas de cohecho. El asunto se originó cuando se denunció que Doheney regaló un terreno en la ciudad de México al gobierno de Estados Unidos para uso de su embajada. "Government took gift from Doheney", The New York Times, 29 enero 1924. El punto que Doheney no tocó ante la comisión fue el arreglo que tuvo con Obregón, en virtud del cual le fueron otorgados derechos de explotación petrolera en la hacienda Juan Felipe en la Huasteca tamaulipeca, a cambio de "diez millones de pesos más de pagos por derechos de perforación". Artículo sin fecha, y nombre de periódico aparecido en ARPADH.

${ }^{19}$ Artículo sin fecha ni nombre de periódico aparecido en ARPDH. 
de 1921, continuarian en los mismos términos, con todas las reformas posteriores y de acuerdo con el pacto De la Huerta-Lamont ${ }^{20}$ En efecto, en el punto 2 del mencionado decreto, se especificaba que los impuestos a la exportación de petróleo debían ser entregados a J. P. Morgan, como dirigente del Comité Internacional de Banqueros, sin que quedara claro si habría o no la intermediación del gobierno obregonista. No obstante lo anterior, los representantes de De la Huerta en los distritos petroleros de Tuxpan y Puerto Lobos exigieron que se les pagara a ellos tales contribuciones. ${ }^{21}$ Los funcionarios de las compañías petroleras declararon que harían el pago señalado el 10 de enero, una vez "que el Departamento de Estado se haya pro-

20 The New York Times, 30 diciembre 1923. En un mensaje interceptado el "secretario en funciones del movimiento" habria escrito a un amigo en Washington que el control de Tuxpan era importante, "no sólo por el número de soldados que se incorporan al servicio, sino porque da al movimiento revolucionario un control absoluto de toda la región petrolera de la que Tuxpan es el puerto". The World, 30 diciembre 1923. El decreto de De la Huerta, transmitido a Seldner en una carta adjunta en la que le autoriza a cobrar tales impuestos, reza en los términos siguientes: Artículo I. El impuesto a la producción de petróleo referido en el decreto del $17 \mathrm{de}$ mayo (¿pasado?) y otras provisiones relativas, será pagado exclusivamente en las oficinas de los cuarteles de la revolución localizadas en este puerto, cuyo monto total deberá ser puesto a su disposición en cualquiera de las instituciones de crédito localizadas en el mismo lugar; Artículo 2. Los impuestos a la exportación del petróleo previstos en el decreto del 7 de junio de 1921, deberán ser recolectados de acuerdo con sus provisiones y enmiendas, y en conformidad con el acuerdo De la Huerta-Lamont y otros acuerdos suplementarios. Artículo 3. Todos los pagos nunciado por la legalidad de tales pagos". 22

En un primer momento, los productores estadunidenses del petróleo mexicano no se mostraron demasiado preocupados por las órdenes de De la Huerta porque, después de todo, Tampico, el principal puerto exportador, estaba firmemente en manos obregonistas. Pero había que tomar una pronta decisión, pues de acuerdo con el calendario de pagos de los petroleros la primera entrega de dinero, por concepto de impuestos a la exportación, debía alcanzar $30 \%$ el 10 de enero; la segunda, 30\% el 20 de enero, y la tercera, $40 \%$ el 25 de ese mes. Los impuestos a la producción debían ser pagados en una sola partida el 25 de cada mes. La amenaza por incumplimiento se expresaba en términos muy simples: las compañías que no pagasen sus impuestos no tendrían petróleo. Seldner hablaba como si todo lo que dijera fuera cierto: "Controlamos todo el distrito petrolero y necesitamos el dinero para financiar nuestras operaciones."23 Finalmente, las compañías petroleras acabaron llegando al acuerdo de que los impuestos por

no hechos a partir de la fecha de publicación de este decreto, de acuerdo con las provisiones se ñaladas arriba, deberán ser considerados nulos y sin efecto. Este decreto deberá ser efectivo a partir del día en que sea publicado en El Dictamen (Veracruz). Dado en los Cuarteles Generales de la Revolución en Veracruz, el 28 de diciembre de 1923. Sufragio Efectivo. No Reelección. Adolfo de la Huerta, en artículo de The New York Times, sin fecha, en ARPDLH.

${ }^{21}$ The New York Times, 12 enero 1924.

22 The New York Times, 2 enero 1924.

${ }^{23}$ Artículo en The Journal of Commerce, en ARPDLH. 
producción de petróleo serían pagados a De la Huerta y no al gobierno de Obregón. Enviaron instrucciones a sus representantes de que entregaran los impuestos a quienes estuvieran realmente en posesión de la zona de operación. Según el derecho internacional, se les explicó, los impuestos podían ser pagados a un grupo revolucionario si controlaba las propiedades, sin que los gobiernos establecidos pudieran hacer ninguna exigencia adicional. ${ }^{24} \mathrm{La}$ reacción del gobierno obregonista no se hizo esperar: Alberto Mascareñas hizo pública la declaración de que la administración mexicana no reconocería pagos de impuestos hechos a la facción delahuertista por las compañías petroleras y que tales pagos serían considerados como actos hostiles. ${ }^{25}$ Sin embargo, el 12 de enero The New York Times dio la noticia de que los rebeldes habían ordenado la suspensión de las operaciones de bombeo de las compañías La Huasteca, El Águila y la Mexican Petroleum, lo que sería "una indicación de que los hombres del petróleo se negaron a pagar las demandas de dinero de los rebeldes", que debían ascender a 20000 pesos como un adelanto del pago de impuestos a la producción. ${ }^{26}$ Las exigencias de los rebeldes a los petroleros se repitieron a lo

${ }^{21}$ The New York Times, 9 enero 1924.

25 The New York Times, 10 enero 1924.

${ }^{26}$ Jorge Prieto Laurens, por su parte, informó que había demandado un préstamo por 20000 pesos de cada una de las compañías petroleras, dándoles cinco días para entregar el dinero, "Oil companies refuse to pay tax to rebels", The New York Times, 12 enero 1924, p. 3. largo de la ocupación de los distritos petroleros, y fueron creciendo en la medida en que sus necesidades militares se hacían más apremiantes.

Martín Luis Guzmán pasó rápidamente de Estados Unidos a Europa, y su misión política ante la Casa Blanca fue continuada por Juan Manuel Álvarez del Castillo. Éste, que había sido vocero de la Cámara de Diputados y embajador en Alemania, fue designado agente confidencial por De la Huerta a fin de impedir que Ross lograse el apoyo de Washington. ${ }^{27} \mathrm{~A}$ lo largo de su misión-exilio, este "agente confidencial del gobierno de facto en México" enfrentó con impotencia una me. dida tras otra de la Casa Blanca contra la causa de los delahuertistas. En su búsqueda desesperada de recursos para cumplir su labor con el mínimo decoro, envió nota tras nota al Departamento de Estado, para protestar, o para tratar de convencer de la importancia de la causa que defendía; buscaba contactos con simpatizantes y al parecer hasta echó mano de un propagandista a sueldo, el exaltado publicista William Bates. En esta línea acudió al argumento del "bolchevismo" de sus oponentes, esgrimido una y otra vez para atraerse al gobierno y a intereses privados de Estados Unidos, quienes se habían declarado enemigos jurados del socialismo a la soviética. Exageró la idea confusa y extendida de que la revolución mexicana era una revolu. ción similiar a la rusa de 1917 , pero en los círculos oficiales ya había ganado terreno la labor de algunos líderes

${ }^{27}$ Álvarez, Memorias, p. 220. 
obreros de Estados Unidos, como Samuel Gompers, presidente de la American Federation of Labor en el sentido de que nada había que temer del "socialismo" de Obregón y Calles. ${ }^{28}$ La desesperación aumentaba en la medida en que los apoyos a Obregón crecían. La mayor frustración de los emisarios delahuertistas en Estados Unidos era no poder entender por qué un Departamento de Estado tan conservador, que se oponía al "radicalismo" en Rusia, podía prestar ayuda al "bolchevismo" en México. ${ }^{29}$

\section{LA DECISIÓN NORTEAMERICANA DE APOYAR A OBREGÓN}

El 15 de diciembre de 1923 el estadunidense Summerlin, encargado de Negocios en México, hizo del conocimiento del secretario de Estado, Hughes, la petición de Obregón para que Estados Unidos le vendiera, entre otros equipos militares, dos cruceros con sus respectivos armamentos, debido a

${ }^{28}$ Andrews, Shoulder, 1991, p. 133.

29 En un momento muy avanzado del proceso de la derrota delahuertista, una versión del argumento "antibolchevique", esgrimido por Álvarez del Castillo fue que los líderes obreros afines al gobierno con sus sindicatos ("ciertos agitadores de las clases laborantes"), gracias a - las armas y municiones norteamericanas, "amenazaban con tomar y confiscar ciertas plantas industriales $[\ldots]$ no sólo en la región petrolera del Golfo, sino de los estados de México, Puebla y Tlaxcala". Por lo tanto era injustificable su actitud ante el pueblo de México, de contribuir con ayuda a esos elementos "destructivos y anarquistas [...] que se están apoderando de propiedad extranjera", J.M. Álvarez del Castillo a Hughes, 31 marzo 1924, RDS, 812.00/27178. que casi la totalidad de la flota mexicana había abrazado la rebelión. Con estos barcos el presidente esperaba tener la capacidad de cortar las comunicaciones de los rebeldes, interceptar sus municiones en tránsito marítimo, tomar el control de Veracruz y Tuxpan y mantener en sus manos la región petrolera de Tampico. Hughes rechazó la solicitud dos días después, sobre la base de que el artículo $18 \mathrm{del}$ Tratado de Armamento Naval prohibía al gobierno de Estados Unidos vender barcos de guerra a gobiernos extranjeros. ${ }^{30}$ Frente a aquella negativa, el señor Ramón Ross se dirigió de inmediato a Washington y logró la aprobación norteamericana para la venta de material de guerra, decisión que se hizo pública el 30 de diciembre. Esta medida causó sorpresa, puesto que todavía estaba fresca la declaración que el presidente Harding había hecho el 23 de abril pasado en la que el gobier-

${ }^{30}$ Esta negativa fue reiterada en más de una ocasión ante la insistencia del gobierno mexicano. El Departamento de Estado hizo una declaración señalando que el Tratado de Armamento Naval de Washington prohibía específicamente a Estados Unidos y a las otras potencias firmantes vender barcos de guerra a cualquier gobierno. El artículo xvir del Tratado hacía imposible cualquier transacción en lo que al gobierno de Estados Unidos se refería. El Tratado no impediría sin embargo la construcción privada de barcos estadunidenses de guerra para México, pero si tales contratos se realizasen, el gobierno de Washington sería requerido bajo ese tratado para informar sobre el hecho a las otras potencias signatarias. Además, el gobierno de Washington se obligaba a vigilar que tales barcos no excedieran en alguna manera los límites de tamaño y armamento impuestos por los países firmantes. "Mexico spring two surprises on Washington", The Sun [?], 3 enero 1924, en ARDPLH. 
no manifestaba su oposición a la venta de sobrantes de equipo militar a cualquier potencia extranjera. ${ }^{31}$

La postura de Washington obedecía al deseo manifiesto del gobierno norteamericano de ver un gobierno estable al sur de su frontera, una vez asumida la probable victoria de los obregonistas. De acuerdo con la declaración oficial de Hughes:

El gobierno mexicano ha presentado una solicitud a este gobierno para que se le venda una cantidad limitada de material de guerra. Este gobierno ha expresado su voluntad de hacer la venta, en vista de las relaciones entre este gobierno y el gobierno mexicano, que fue formalmente reconocido el pasado septiembre, y de la importancia del mantenimiento de la estabilidad y el orden constitucional en la república vecina. ${ }^{32}$

El Departamento de Estado consideró que ningún precedente peligroso se había establecido con este apoyo, y declaró que no estaba en contra de la postura de Harding en relación con la venta de material bélico a otros

31 La declaración sobre políticas de venta de equipo militar sobrante a potencias extranjeras apareció en sendas cartas que el presidente Harding envió a los secretarios Weeks (Guerra) y Denby (Marina), cuando al parecer Polonia había hecho una solicitud formal para la compra de rifles y municiones sobrantes a Estados Unidos. The New York Times, 30 diciembre 1923. En el momento de su publicación, las cartas del presidente Harding fueron consideradas como una firme prohibición más que explícita de cualquier venta de material de guerra a los países extranjeros.

32 Citado por The New York Times, 30 diciembre 1923, y The World, 30 diciembre 1923. gobiernos. Por el contrario, este material suministrado al gobierno mexicano tenía como objetivo desalentar la guerra y el militarismo, dentro de la lógica de mantener la paz a través del mundo. Por tanto, la venta de armas a México era una cuestión totalmente diferente a la planteada por "un poder balcánico" que solicitó 500000 rifles a Harding; ello "habría podido crear inquietud militar en los Balcanes", y conducido a una carrera armamentista entre "ciertas" potencias europeas y quizás a la guerra. En las últimas horas de 1923, el gobierno estadunidense hizo un nuevo anuncio oficial sobre su decisión de vender material a Obregón en los términos siguientes:

Este gobierno está proporcionando una cantidad limitada de material de guerra al gobierno mexicano porque tal acción es en interés de la estabilidad y el orden. El intento que está siendo hecho para derrocar al gobierno establecido en México ha sido resuitado de las animosidades y amarguras derivadas de la campaña presidencial para seleccionar al sucesor del presidente Obregón. Es altamente importante que México se aparte de los precedentes anteriores y determine la sucesión a la presidencia de tal pais por métodos pacíficos y constitucionales. ${ }^{33}$

Tocaría al secretario de Guerra Weeks hablar de algunos detalles de la venta de armamentos al gobierno mexicano:

Este gobierno ha vendido al gobierno mexicano 5000 rifles Enfield, modelo

${ }^{33}$ New York Tribune, 1 enero 1924. 
de $1917 ; 5000000$ de cargas calibre .30; municiones y ocho aeroplanos DH4 (DeHavilland 4), cuyos términos de venta fueron la mitad en efectivo y la mitad en treinta días. Estos artículos no cubren la lista entera solicitada originalmente, pero el gobierno mexicano encuentra que ellos responden a los requerimientos presentes. ${ }^{34}$

El primer pago sería realizado a través de una orden telegráfica a favor de la Guaranty Trust Company, y el material sería enviado en las siguientes 24 horas. El precio no fue revelado, pero se llegó a calcular como cercano al medio millón de dólares, incluyendo los aviones, del cual la mitad habría sido entregada de manera simultánea al envío del material. ${ }^{35}$ Tres meses después del estallamiento del conflicto se estimó que más de 1000000 de dólares de material de guerra había sido vendido por Estados Unidos al gobierno de Obregón en transacciones virtualmente continuas a partir del primero de enero de 1924. El Departamento de Guerra de Estados Unidos reveló que cerca de ocho ventas fueron negociadas, incluyendo el envio de 2900 bombas aéreas, 33 ametralladoras, 15100 rifles Enfield, 5000 rifles rusos, 5010000 cargas de municiones para rifles y 11 aeroplanos DeHavilland 4 . Los envios y las entregas fueron hechos en el mayor secreto para ocultárselos a las fuerzas rebeldes. ${ }^{36}$ Los rifles y las municiones se

${ }^{34}$ The New York Times, 5 enero 1924.

35 Artículo sin título ni nombre de periódico, 10 enero 1923 , en ARPDLH.

36 The New York Times, 13 marzo 1924. encontraban en San Antonio, Texas, y en Fort Bliss, y fueron entregados a los representantes del gobierno mexicano para su transporte a México. Los aeroplanos provendrian de Fairfield Depot en Dayton, Ohio, y fueron enviados en partes por un medio tampoco revelado.

Éste fue el punto de partida de las acciones norteamericanas en contra de los rebeldes delahuertistas. Iuego la comunicación telegráfica entre Veracruz y Nueva Orleans fue suspendida, lo que era un golpe considerable contra el sistema de comunicaciones de los alzados. ${ }^{37}$ La comunicación telegráfica con Veracruz sería restablecida más tarde por el crucero militar Tacoma, que serviría de enlace con las estaciones navales y el ejército norteamericano en el territorio de Estados Unidos. Este buque, procedente de Galveston, se estacionó en el arrecife veracruzano Blanquilla. Armado con ocho cañones de cinco pulgadas y dotado con una compañía de marinos lista para desembarcar, fue una presencia intimidante $y$ de vigilancia de las actividades rebeldes hasta que fue hundido por una tormenta tropical. 38

La decisión de Washington de vender municiones a México fue con-

${ }^{37}$ De acuerdo con Clarence Liddy, gerente de la compañía telegráfica en Nueva York, "nues. tra franquicia es con el gobierno de Obregón [...] el presidente Obregón ha ordenado la suspensión de los cables y nosotros no tenemos más alternativa que hacerio, o perder nuestra franquicia si los obregonistas ganan la revolución". "De la Huerta orders 5000 rifles bought here to test rights", The New York Times, 6 enero 1924.

${ }^{38}$ The New York Times, 6 enero 1924. 
gruente con su política continental de desalentar movimientos armados contra gobiernos establecidos. Fue también un mensaje en el sentido de que Estados Unidos no solamente se oponía al derrocamiento de gobiernos "acreditados" en este hemisferio, sino incluso que estaba dispuesto a colaborar, por medio de la ayuda militar, a sofocar los movimientos rebeldes y hasta a intervenir directamente. La explicación más razonada de la política latinoamericana y mexicana, en particular de Coolidge, fue expuesta por el secretario de Estado, Hughes, en un discurso pronunciado el 23 de enero de 1924 ante el Council of Foreign Relations de Nueva York. En él describió su política como "la mayor contribución dentro de nuestro poder, y de acuerdo con nuestras tradiciones establecidas e interés manifiesto, a la causa de la paz mundial. Este hemisferio debe ser un ejemplo de paz". Agregó que "nosotros vemos con confianza la creación de una unidad de sentimientos de las repúblicas americanas contra el recurso al arbitrio brutal de la fuerza en la solución de las controversias políticas". Para alcanzar este fin "Estados Unidos gustosamente da su cooperación". Hablando en el apartado titulado "Cuestiones y negociaciones recientes", señaló:

Después de este resultado feliz (la firma de dos convenciones de reclamaciones, en virtud de las cuales el gobierno de Obregón tuvo el reconocimiento diplomático de Estados Unidos) y cuando estäbamos esperando un periodo de calma y de ventajas para ambos pueblos, repentinamente hubo un intento de derrocar al gobierno establecido de
México por la violencia. Es claro que el propósito de los comprometidos en esta empresa armada simplemente es determinar por medios forzosos la sucesión del presidente Obregón. No es un instinto revolucionario en favor de las aspiraciones de un pueblo oprimido; es un asunto de políticas personales. Es un esfuerzo por tomar la presidencia, es decir, una subversión de todos los medios legales y constitucionales. Los rebeldes, buscando el derrocamiento del gobierno establecido, han tomado posesión de ciertas partes del territorio mexicano y están o exigiendo tributos al comercio norteamericano pacífico y legítimo, o intentando obstruirlo y destruirlo.

El secretario Hughes tocó luego la solicitud del gobierno mexicano de comprar armas y municiones a Estados Unidos. Rehusar, dijo, sería dar la espalda al gobierno con quien recientemente se restauraron las relaciones amistosas, y "hubiera dado un estímulo poderoso a aquellos que están intentando arrebatar las riendas del gobierno por la fuerza". De haber seguido tal camino, el gobierno de Washington "hubiera incurrido en una grave responsabilidad por los problemas consecuentes", mientras que el contestar afirmativamente la solicitud de armas no significaba "una intervención ni una invasión a la soberanía de México". Él sostuvo que las ventas "no se apartaron del principio establecido por la política del presidente Harding respecto a la venta de armas" que, dijo, de ninguna manera excluyó la provisión de armas "para ayudar en la sofocación de los ataques insurrectos al orden público en un estado vecino cuyo desa- 
rrollo pacífico es especialmente importante para nosotros". 39

EL EMBARGO Y OTRAS HOSTILIDADES ANTIRREBELDES DEL. GOBIERNO ESTADUNIDENSE

La asistencia militar de Washington a Obregón fue acompañada del embargo de armas a los rebeldes, una vieja práctica de presión en el manejo de los asuntos mexicanos. Desde el momento en que se preparaban los envíos al gobierno obregonista, Washington iba haciendo cada vez más patente su desaprobación a la venta de armas porfabricantes y comerciantes estadunidenses a los alzados. Por lo demás, fuera de los almacenes del gobierno no había material en las cantidades deseadas por los delahuertistas, ya que el Departamento de Guerra fabricaba sus propias armas bajo patentes federales desde la primera guerra mundial. Despachos provenientes de Washington hicieron pensar a los rebeldes que, a pesar de algunas señales desalentadoras, no existía ningún embargo de armas en su contra, y que ninguna ley sería violada si este país no era usado como base de operaciones contra el gobierno mexicano. De la Huerta de inmediato decidió tantear su situación ante Estados Unidos por medio de un intento de compra de 5000 rifles, 10 ametralladoras, 3000000 de cartuchos para rifle, así como 1000000 de municiones para ametralladora. ${ }^{40} \mathrm{El}$ encargado directo de la operación era Teodoro Fréziers, quien procuraría "no violar de ninguna manera las leyes de Estados Unidos". Se dirigió al coronel George R. Shanton, jefe del Departamento de Justicia Federal en este puerto, y lo puso al tanto de sus planes. Shanton le respondió que debía contar con la aprobación de Washington y pidió instrucciones. El secretario Hughes le contestó que el Departamento "desalentaba" tales envíos, y que quienes hicieran embarques de armas "lo harían enteramente bajo su propio riesgo". 41

Los rebeldes aprovecharon hasta el último momento para adquirir armas en Estados Unidos, antes de que entrara en vigor el embargo total. Se informó que habían logrado consignar un importante envío de municiones y armamento como textiles en Nueva York, mismos que llegaron a Veracruz sin problemas. ${ }^{42}$ El embargo se inició el 7 de enero, a través de una proclama presidencial. Las protestas del gobierno de Obregón contra las gestiones delahuertistas de compras en Nueva Orleans, Norfolk, Nueva York y San Francisco llevaron a esta iniciativa de Calvin Coolidge. La proclama, desde luego con dedicatoria, hizo excepción específica de "las exportaciones de armas o municiones de guerra que han sido aprobadas por el gobierno de Estados Unidos para el gobierno de México $[. .$.$] y las armas y municiones para$
39 Artículo en periódico sin nombre, 24 enero 1924, en ARPDLH, Excélsior, 24 enero 1924; The New York Times, 24 enero 1924.
${ }^{40}$ The New York Herald, 4 enero 1924.

41 The New York Times, 7 enero 1924.

${ }^{42}$ The World [?], 10 enero 1924, en ARPDLH. 
propósitos industriales y comerciales, con el consentimiento del secretario de Estado". La resolución establecía una penalidad, por la violación del embargo, consistente en una multa no mayor de los 10000 dólares, o prisión no más allá de dos años. Bajo esta medida el Departamento del Tesoro sería requerido inmediatamente para negar despachos aduanales en puertos y puntos fronterizos de envíos de armas de cualquier carácter a México, excepto cuando la aprobación explícita del secretario Hughes hubiera sido obtenida. El Departamento de Justicia arrestaría a las personas que conspiraran y violaran con ello las leyes de neutralidad. ${ }^{43}$ De manera simultánea, el gobierno instruyó a bancos de Nueva York y Nueva Orleans, donde existían fondos rebeldes, a mantener una severa vigilancia de los depósitos para que no fueran retirados para la compra de armamentos. ${ }^{44}$ Con este embargo, a De la Huerta no le iba a quedar más que contar con las armas y municiones en su poder en México, o con las que pudieran ser adquiridas ilegalmente en el mismo Estados Unidos. ${ }^{45} \mathrm{Cuba}$ y Guatemala, por su parte, declararon su neutralidad, y presumiblemente habrían impedido el envío de armas a De la Huerta. La realidad fue que el presidente cubano Alfredo Zayas, de común acuerdo con el ascendente candi-

43 The Journal of Commerce, 8 enero 1924. The New York Times, 8 enero 1924.

${ }^{44}$ The World [?], 10 enero 1924, en ARPDLH.

${ }^{45} \mathrm{Se}$ informó, por ejemplo, de la consignación frustrada de 4000 bombas lacrimógenas en Nueva York con destino a Veracruz, The New York Times, 13 enero 1924. dato liberal Gerardo Machado, vendió armas del ejército de Cuba a los delahuertistas. ${ }^{46}$

Contrariamente a lo que afirmaban sus críticos congresistas, la administración no había establecido nuevos precedentes en materia de envío de armas a México. La proclama de otro embargo para impedir los envíos privados de armas a la facción de De la Huerta sólo puso a la política estadunidense en línea con métodos que habían sido consistentemente seguidos desde 1912. Recién caído Porfirio Díaz, el gobierno de Estados Unidos empezó a usar su control del abastecimiento de armas y municiones con el propósito deliberado de influir en los acontecimientos en México. A partir de aquí, el instrumento del embargo fue establecido o modificado en ocasiones diferentes, cada vez con el propósito de maniobrar en México de acuerdo con los deseos y necesidades particulares de Washington. No había pues ningún elemento nuevo en cuanto a la ayuda al gobierno mexicano, que estaba en apuros, excepto el hecho de que las armas fueron vendidas directamente a Obregón por el gobierno estadunidense.

Esta decisión del presidente Coolidge dio la estocada de muerte a las esperanzas de los rebeldes de que su levantamiento se extendiera por todo México. "Viajeros provenientes de Veracruz -afirmaba The New York Times- dicen que los rebeldes son

46 Entrevista del autor con el embajador Gilberto Bosques, quien participó en las negociaciones y compras de armas para los rebeldes en Cuba. México, 11 octubre 1994. 
incapaces de mantener una batalla porque les faltan municiones. Se estima que las fuerzas rebeldes de Veracruz y Oaxaca no tienen suficientes municiones para una sola batalla de envergadura". Lo mismo ocurrió pronto en Jalisco, donde la preponderancia aplastante de municiones, equipo aéreo y artillería de las fuerzas del gobierno obligaría a los rebeldes a abandonar sus posiciones. En este frente, Obregón hizo gala de su celebrado genio militar al proceder con lentitud hasta no tener antes la seguridad de que su ejército estuviera totalmente sobrado de equipos, reservas y municiones. 47

El gobierno de Obregón pidió permiso a Estados Unidos para que un cuerpo de tropas pudiese atravesar su territorio desde Naco, Arizona hasta un punto en Texas para entrar de nuevo a territorio mexicano, con el propósito de acelerar el traslado de tropas desde Sonora al oriente del país. Aunque la decisión correspondía hacerla a Washington, los gobernadores de Arizona, Nuevo México y Texas debían dar su consentimiento. La respuesta a la petición obregonista fue el anuncio del secretario Hughes en que expresaba, entre otras cosas, que existian precedentes a considerar:

Permisos similares han sido extendidos en el pasado, la última vez en octubre de 1915, y otra en noviembre de 1916, cuando al gobierno de facto de México, encabezado por el señor Carranza, le fue permitido transportar tropas mexicanas de la frontera texana, a través de

47 The New York Times, 10 enero 1924.
Estados Unidos, al estado de Sonora, México, donde vidas y propiedades americanas estuvieron en serio peligro por las operaciones de bandas revolucionarias mexicanas. ${ }^{48}$

Los gobernadores de los estados mencionados, amigos personales de Obregón, dieron su consentimiento, a pesar de los temores de sufrir represalias por parte de los rebeldes, acordándose del ataque de Villa a Columbus, Nuevo México. El propósito del paso de estas tropas a un punto del sur de la frontera texano-mexicana era reforzar las posiciones gobiernistas en torno a los ocupados campos petroleros aledaños a Tampico, en poder de los rebeldes. Eran 2000 soldados, veteranos de batallas contra Estrada en el frente occidental, bien equipados con las armas estadunidenses y con pocos signos de fatiga, bajo el mando del general Jesús María Aguirre. Originalmente se dirigirían a Laredo, pero lo harian por El Paso debido a las reticencias del gobernador texano en funciones, $T$. W. Davison, a quien el mismo Hughes convenció con la garantía de que las vidas y propiedades de los texanos serían salvaguardadas. ${ }^{49} \mathrm{~J}$. M Álvarez del Castillo "manifestó su sorpresa" de que fuerzas yaquis fueran transportadas por territorio norteamericano desde Naco, so capa de que su destino fuera servir en regiones donde los intereses norteamericanos pudiesen estar en "grave peligro", tal y como lo expresó el gobierno. Álvarez dijo que las vidas y propiedades norteamerica-

48 The New York Times, 18 enero 1924.

${ }^{49}$ Evening Mail, 20 enero [?], en ARPDLH. 


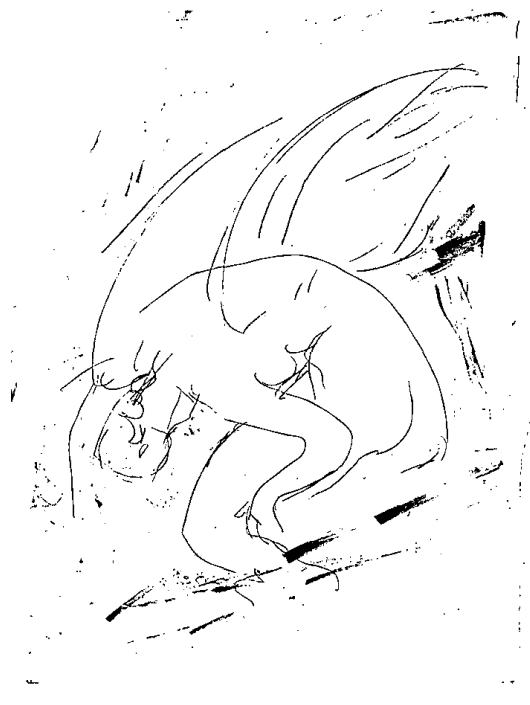

nas no estaban en peligro en territorio bajo control delahuertista, que él estaba observando la ley de la guerra, $e$ intentaba proteger las vidas e intereses de los extranjeros. ${ }^{50}$

El gobierno de Estados Unidos hizo valer también su alianza con Obregón aplicando con sobrado celo sus leyes de neutralidad. Rubén Zicarra, representante de De la Huerta en San Antonio, y alguna vez presidente de la Cámara de Diputados, y Toribio Villaseñor, ex gobernador de Guanajuato bajo Carranza, fueron tomados en custodia por agentes del Departamento de Justicia y agentes de la United States Marshal's Office acusados de reclutar soldados y de emprender una expedi-

50 The New York Times, 21 enero 1924. ción militar contra el gobierno mexicano. Su arresto había sido antecedido por la aprehensión de tres rebeldes en Eagle Pass. El general Cándido Aguilar, uno de los principales dirigentes del movimiento rebelde, fue detenido en San Antonio bajo el cargo de violar las leyes de neutralidad. William J. Burns, funcionario del Buró de Investigaciones de Estados Unidos, expresó que no existian órdenes para emprender arrestos masivos del grupo de De la Huerta pero que funcionarios locales habían estado alertas desde el principio de la insurrección, con instrucciones de hacer cumplir la ley. ${ }^{51}$ El gobierno mexicano, por su parte, hacía llegar información sobre movimientos de agentes delahuertistas, mismos que eran atendidos puntualmente por el gobierno de Estados Unidos. Un informe de la Embajada de México señalaba que "parecía" haber arribado a Nueva Orleans, el 27 de febrero de 1924, un barco procedente de Frontera, con el general Alfonso de la Huerta (hermano de don Adolfo), Jesús Triana, Aurelio Aguilar, Enrique Barón Obregón y José L. Rodríguez, quienes se dirigian a Tucson, Arizona, "a donde, según parece, llevan el propósito de desarrollar actividades en favor de la fac-

51 The New York Times, 19 enero 1924. El Departamento de Justicia mantenía, por lo demás, una cercana vigilancia sobre los partidarios activos de la rebeldía en lugares muy concurridos por ellos, como San Antonio Texas. Un informe de Gus T. Jones, agente especial en San Antonio, es muestra de esta práctica. Su extracto menciona a una buena cantidad de "posibles transgresores de la ley". Gus T. Jones al Assistant Attorney General, 1 julio 1924, RIDS, 812.00/27310. 
ción rebelde, y encaminadas a iniciar movimientos sediciosos en la región fronteriza de Sonora, México". ${ }^{52}$ Así, cuando el general Alfonso de la Huerta, llegó a Arizona, fue apresado por la policía local de Tucson y entregado clandestinamente a las autoridades mexicanas de Nogales. De la Huerta murió a causa de las torturas infligidas durante su detención, y su cadáver fue exhibido, para escarmiento de todos, en la plaza pública de Nogales, Sonora. ${ }^{53}$

\section{PRESENCIA DE BARCOS DE GUERRA DE ESTADOS UNIDOS EN AGUAS MEXICANAS}

El anuncio del bloqueo de Tampico por De la Huerta elevó significativamente el grado de participación estadunidense en el conflicto. En virtud del decreto del 12 de enero de 1924, De la Huerta estableció el día siguiente como el del inicio de la medida con la salvedad de que a los buques mercantes deseosos de refugiarse en este puerto se les darian tres dias de gracia para hacerlo, y todos los que desearan abandonarlo tendrían seis días más. Fuera de estos plazos, cualquier buque que entrara o saliera de Tampico sería con-

52 Embajada de México a Departamento de Estado, nota recibida por éste el 5 de marzo de 1924 RDs, 812.00/27082; Asistente del abogado general a Hughes, 14 marzo 1924, RDS, 812.00/27114; Téllez a Hughes, 8 de abril de 1924 , RDS, 812.00/27190. Esta última nota localiza a Alfonso de la Huerta y Carlos Díaz en Phoenix, Arizona.

${ }^{53}$ Entrevista del autor con el ingeniero Arturo de la Huerta, hijo de don Adolfo de la Huerta, Guaymas, Son., 22 octubre 1994.

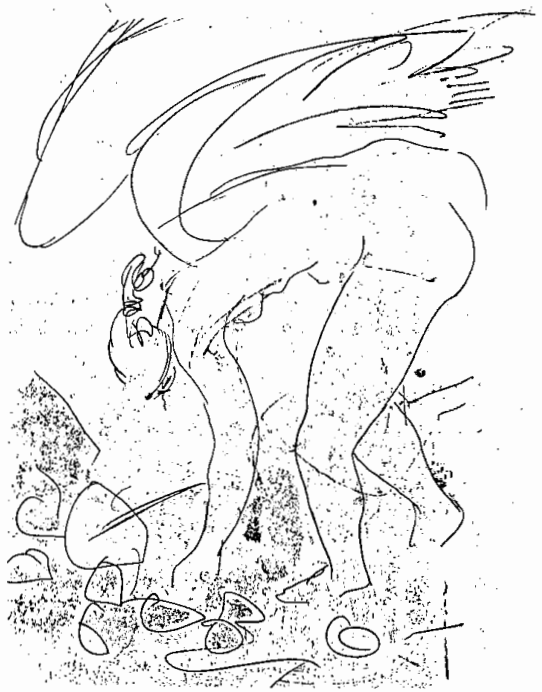

siderado enemigo. ${ }^{54}$ La reacción de Estados Unidos contra la medida fue inmediata y contundente. El Departamento de Estado declaró que protestaría "de la manera más vigorosa" contra el bloqueo al ser "una interferencia totalmente innecesaria con el comercio", por lo que tal medida "constituiría un acto de absoluta desconsideración hacia los intereses estadunidenses". 55 Por otro lado, el secretario de Estado Hughes señaló que la exportación de productos del petróleo de Tampico era de la mayor importancia para Estados Unidos, por lo que instruyó al

54 The New York Times, 15 enero 1924. Cónsul Wood a Hughes, 12 enero 1924, RDs, $812.00 / 26763$.

55 The New York Times, 16 enero 1924. 
cónsul estadunidense Wood, de Veracruz, a comunicar "a la persona que ordenó el bloqueo que Estados Unidos protesta vigorosamente contra cualquier intento $[\ldots]$ de cortar las comunicaciones entre Tampico y Estados Unidos", así como "su derecho a cuestionar la legalidad del bloqueo propuesto o cualquier operación dirigida contra los cargueros y buques estadunidenses" ${ }^{56} \mathrm{~A}$ los pocos días, considerando Hughes que no se había emprendido "ningún paso" para remover esta amenaza después de su enérgica protesta, ordenó a Wood que informara a De la Huerta que el gobierno de Estados Unidos había dado instrucciones al crucero Richmond de que se dirigiera a Tampico "a fin de proteger adecuadamente el comercio pacífico y legítimo de Estados Unidos en ambas direcciones, de cualquier interferencia causada por el bloqueo". 57

El Richmond era un navío armado con doce cañones de 6 pulgadas de gran calibre y equipado con una poderosa instalación de radio que le permitía a Washington establecer comunicación directa e instantánea con Veracruz. A este barco, bajo el mando del contralmirante MacGruder, le fue ordenado que se dirigiera a ese puerto a fin de recoger a la tripulación del averiado Tacoma y que partiera de inmediato hacia Tampico con instrucciones de proteger adecuadamente el comercio pacífico y legítimo entre Estados Unidos y ese puerto de cual-

56 Hughes a Wood, 15 enero 1924, RDS, 812.00/26762.

${ }^{57}$ Hughes a Wood, 19 enero 1924, RDS, $812.00 / 26763$. quier interferencia por el bloqueo. ${ }^{58}$ De acuerdo con el secretario de Marina, Denby, era imprescindible no abandonar al Tacoma hasta que hubieran sido aseguradas armas y municiones. "Si es dejado sin su tripulación, será desde luego saqueado por las fuerzas rebeldes que recibirían de este modo un refuerzo considerable en materia de municiones", 59 posible evidencia de que el Tacoma estaba preparado para hacer un desembarco armado. Al final, una parte de la tripulación quedó en este barco esperando su irremediable hundimiento en el arrecife Blanquilla.

El proyectado bloqueo delahuertista de Tampico tenía además dificultades técnicas para ponerse en marcha, a no ser utilizando minas porque los buques de que podían disponer los rebeldes eran pocos y de poca consideración, sin contar con la advertida oposición de Washington a tal medida. El único intento de conquistar Tampico por mar tuvo resultados muy pobres. Los buques rebeldes Zaragoza y Tampico, que lograron impedir la entrada de seis tanqueros y uno de carga, bombardearon con cuatro tiros la entrada del puerto pero fueron rechazados de inmediato por sus defensores. Luego encañonaron los suburbios de Varadero, en la margen izquierda del río Pánuco, destruyendo algunas casas de chinos para luego retirarse y desaparecer. ${ }^{60}$

${ }^{58}$ Hughes a Wood, 18 enero 1924, RDS, $812.00 / 26804 a$ y $812.00 / 26804$ b, artículo en periódico sin nombre, 17 enero 1924 , en ARPDLH.

59 Denby a Hughes, 18 enero 1924, en RDS, $812.00 / 26810$.

60 The New York Times, 18 enero 1924. 
El plan contingente de De la Huerta para aislar Tampico era el de sembrar minas en sus aguas, así como en las de Frontera, Puerto México y Veracruz. A este respecto, el cónsul Wood fue nuevamente instruido para que le comunicara a De la Huerta que Estados Unidos se reservaba el derecho de aplicar las "medidas apropiadas", en el caso de que no se removieran de inmediato tales obstáculos a la navegación. ${ }^{61}$ Según Wood, a él ya se le había asegurado "informal y no oficialmente" que si al cañonero gubernamental Bravo no se le permitía abandonar Nueva Orleans durante el conflicto, el bloqueo sería levantado y los puertos estarían libres de minas. ${ }^{62} \mathrm{~A}$ la postre y para evitar problemas mayores, los rebeldes acordaron levantar de manera absoluta el proyectado bloqueo, ${ }^{63}$ asi como dejar en suspenso el minado de las aguas próximas. Los rebeldes llegaron a afirmar que el bloqueo "técnico" a Tampico sería sustituido por una política bajo la cual los buques mercantes extranjeros serían advertidos de que, si ellos entraban a la zona de un posible bombardeo, lo harían bajo su propio riesgo por ser zona de bata-

${ }^{61}$ Hughes a Wood, 21 enero 1924, RDS, 812.00/26788. La respuesta se dio en Wood a Hughes, 21 enero 1924, RDS, 812.00/26827.

62 Wood a Hughes, 19 enero 1924, RDs, 812.00/26797; Wood a Hughes, 23 enero 1924, RDS, 812.00/268449. Sobre noticias del levantamiento de las minas de Frontera, Puerto México y Veracruz, Zubarán a Wood, 23 enero 1924, en RDS, 812.00/26923.

63 Zubarán a Wood, RDS, 812.00/26782, Wood a Hughes, 22 enero 1924, RDS, 812.00/ 26837. llas navales. ${ }^{64}$ Tampoco esta medida pudo ser aplicada por los rebeldes.

El gobierno mexicano, a pesar de que el apoyo de Washington estaba en buena parte decidiendo la contienda en su favor, veía en las posibilidades de una intervención directa un alto riesgo político capaz de revertir las ganancias obtenidas hasta el momento al generar eventualmente un frente nacionalista y antiobregonista por añadidura.

La preocupación de la cancillería de México en este sentido se revelaría en una comunicación de este tipo:

Respecto a la amonestación hecha a és-
tos [los rebeldes] por el gobierno de Es-
tados Unidos de verse en la precisión de
adoptar medidas apropiadas para pro-
teger las vidas de sus ciudadanos y sus
intereses, mi gobierno desea expresar
al de V. S. la esperanza de que no haya
lugar a ello, en bien del mutuo acuerdo
que hasta hoy ha existido tan felizmen-
te entre ambos. La benevolencia que Es-
tados Unidos ha demostrado a México
hace esperar que las fuerzas de aquéllos
no se ejercitarán dentro del territorio
nacional, pues lo contrario, como no se
ocultará al gobierno de V. S., pondría al
gobierno mexicano en muy penosa si-
tuación. 65

La "liberación" de las aguas del Golfo del control delahuertista no preocupaba solamente a Obregón, sino también a los petroleros estadunidenses cuyas rutas de transporte se ubicaban

64 "Artículo en periódico desconocido, fecha desconocida", en ARPDLH.

${ }^{65}$ Aarón Sáenz a George T. Summerlin, encargado de Negocios de los Estados Unidos en México, 25 enero 1924, RDS, 812.00/26694. 
precisamente en esta zona. Solamente así se explica la persistencia del asedio naval antirrebelde. Después del envío del Tacoma y el Richmond tocó el turno al crucero Omaha, que estaba bajo el mando del capitán Kittelle, con una tripulación de mil "chaquetas azules" y una guardia marina de aproximadamente cuarenta marinos. Lo acompañaban los destructores Corry, Hull, MacDonough, Farenhol, Sumner y Shirk, y el barco de reparaciones Prometheus, que fueron enviados desde Panamá hasta Veracruz. El Omaha llevaba también un avión. ${ }^{66}$ Esta sorpresiva decisión de Washington, según The New York Times, fue resultado de una conferencia entre Hughes y los intereses petroleros en México. Éstos se quejaron de que los rebeldes estaban bloqueando los conductos, obstruyendo los embarques e intentando recolectar un impuesto pagadero al gobierno mexicano por producción y exportación de petróleo ${ }^{67}$ Esta demostración sobrada de fuerza contra los rebeldes buscaba desalentar de manera completa y definitiva cualquier acción rebelde sobre el estratégico puerto petrolero de Tampico -el único puerto en manos del gobierno-, por mar o por tierra, que pudiera poner en peligro el libre flujo del hidrocarburo de México a los puertos estadunidenses. Una vez abandonado el proyecto delahuertista de bloquear el puerto de Tampico, el Departamento de Estado anunció que tanto el Richmond como el crucero Omaha y los seis destructores debían retirarse de

66 The New York Times, 20 enero 1924.

67 The New York Times, 20 enero 1924. aguas mexicanas, así como el U.S. S. Tulsa, pero debían estar listos para cualquier eventualidad. El Prometheus debía permanecer en Veracruz atendiendo lo rescatable del Tacoma. ${ }^{68}$

Sin embargo, ya en camino de vuelta a sus bases tanto al Richmond como al Omaha y sus seis destructores les fue ordenado regresar como una medida de precaución ante el nuevo impulso militar en el frente veracruzano, después de que tropas federales habían capturado Estación Esperanza. ${ }^{69}$ Esta decisión, al parecer, obedeció a tres razones. En primer lugar, estaban los excesos de las tropas obregonistas en sus avances en Veracruz, causa de alarma entre los extranjeros en la región, quienes veían en los buques norteamericanos cerca de las costas un elemento de seguridad. ${ }^{70}$ En segundo lugar, se presumía que, en el caso de una batalla en el puerto de Veracruz entre obregonistas y delahuertistas, "capaz de afectar a vidas e intereses norteamericanos", los marinos debían estar listos para intervenir. ${ }^{71}$ Finalmente, se percibía la necesidad de llenar un probable vacío de poder, en el tiempo transcurrido entre la huída de los rebeldes a lugares más seguros y la llegada de las nuevas autoridades obre-

68 State Department to American Embassy in Mexico, 24 enero 1924, RDs, 812.00/26848. The Tribune, Nueva York, 26 enero 1924.

69 The New York Times, 31 enero 1924. Wood a Hughes, 1 y 2 febrero 1924, RDs, 812.00/ 26907, y Wood a Hughes, 3 febrero 1924, RDS, $812.00 / 26917$.

${ }^{70}$ Wood a Hughes, 2 febrero 1924, RDS, $812.00 / 26915$

71 The Tribune's Washington, 5 febrero 1924. 
gonistas. El Richmond permaneció en aguas mexicanas hasta el 15 de febrero. ${ }^{72}$ Pero Veracruz no era la única región a atender por la marina norteamericana. Más al sur, operaron otros buques como el U.S. S. Tulsa, al que le fueordenado transportar refugiadosdesde Tuxpan y permanecer en actitud de observación, vigilancia y espera frente al puerto de Progreso, Yucatán. El U.S. S. Tulsa fue seguido en sus actividades en este lugar por el U. S. S. Cleveland, el U.S. S. Denver, y el U. S. S. Galveston. ${ }^{73}$ El Tulsa llegó a Progreso el 29 de febrero y se retiró el 6 de abril.

En el Pacífico, al U. S. S. Milwaukee, por su parte, le fueron ordenadas misiones de vigilancia y espera en Manzanillo y Acapulco, en "previsión de desórdenes" ${ }^{74}$ El principal temor que existía en Acapulco era la llegada de las llamadas "fuerzas agraristas" aliadas del gobierno, quienes eran vistas por el cónsul Bucklin de Acapulco como punto menos que hordas salvajes, por lo que era imprescindible la presencia de una fuerza naval. ${ }^{75} \mathrm{El} \mathrm{U}$. S. S. Milwaukee fue enviado a Acapulco y Manzanillo el 22 de febrero, desde Ampala, Honduras, donde había estado estacionado con el "propósito de

72 Wood a Hughes, 15 febrero 1924, RDs, 812.00/26997.

${ }^{73}$ Hughes to Secretary of the Navy, 1 marzo 1924, RDS, 812.00/27071; Hughes a Wood, 28 febrero, RDS, 812.00/27038; Cónsul R. L. Rankin a Hughes, 22 julio 1924, RDs, 812.00/27335.

${ }^{74}$ Hughes a Summerlin, 11 de febrero de 1924, RDS, 812.00/26978, vicecónsul Aguirre en Manzanillo a Hughes, 11 febrero 19124, RDS, $812.00 / 26981$.

75 Bucklin a Hughes, 14 febrero 1924, RDS, $812.00 / 27121$. proteger vidas y propiedades de los ciudadanos americanos", debido a las circunstancias revolucionarias en ese país. ${ }^{76}$ El capitán de otro barco de guerra anclado en Acapulco, el U. S. S. Cincinnati, el almirante C. P. Nelson, fue intermediario en la transferencia del poder de los rebeldes en huída de Acapulco (encabezados por el general Ambrosio Figueroa y el coronel Rosendo Robles) a las fuerzas federales a bordo del Progreso con el propósito de evitar un vacío de poder que pudiera ser ocupado por los "desalmados agraristas" que bajaban de las montañas hacia Acapulco, así como de proteger a refugiados, sobre todo a súbditos españoles. ${ }^{77}$ Más aún: a petición del "jefe de las fuerzas federales, un general Estrada", el capitán Nelson estuvo a punto de desembarcar fuerzas armadas sin que mediara la amenaza a ningún interés norteamericano ni alguna provocación grave, situación que, de haberse dado, hubiera causado serios trastornos en las relaciones entre México y Estados Unidos. Los destructores norteamericanos Melvin (335) y el Kennedy (306), por su parte, llegaron a la bahía de Salina Cruz, y los habitantes de este lugar creyeron que llegaban a petición del gobierno mexicano para proteger la llegada del secretario mexicano de Guerra, Francisco Serrano, si bien el propósito declarado de sus capitanes era que lle-

76 The New York Times, 27 febrero 1924.

77 Vicecónsul Harry K. Pangburn en Acapulcoa Hughes, 13 marzo 1924, RDS, 812.00/27160. Hughes a Summerlin, 14 marzo 1924, RDS, $812.00 / 27115$. 
gaban a reparar las calderas del Kennedy. ${ }^{78}$

La "guerra marítima" del obregonismo fue ganada sin que se disparara un solo tiro, ni mexicano, ni estadunidense. El despliegue naval de Estados Unidos en aguas mexicanas y en las cercanas a ellas, con todo su poderío, convenció a los rebeldes de la inutilidad de llevar adelante cualquier iniciativa ofensiva en las zonas marítimas. Con ello, se liquidó lo que fue pieza principal de la victoria que nunca llegó. El delahuertismo quedó confinado entonces a una zona larga en la costa del Golfo y a algunas zonas aisladas del resto del país, entre la zona federal en el este y el asedio naval de Estados Unidos en el oeste. En este escenario patético, no quedaba más futuro que el avance gubernamental sobre las áreas caídas al calor de la sorpresa del levantamiento, y la retirada del liderazgo rebelde hacia el sureste, donde quedaría disuelto en definitiva.

\section{EPÍLOGO}

Las derrotas de Esperanza en el frente oriental, y de Ocotlán en el occidental fueron golpes mortales a la causa de los rebeldes. En ambos contaron decisivamente las existencias de armas, municiones y aparatos de guerra, situación en la que, según los rebeldes, el virtual equilibrio existente entre las dos fuerzas nacionales en conflicto se había roto por la ayuda de Estados Unidos a Obregón. A fin de fortalecer la

78 Vicecónsul Harold C. Wood en Salina Cruz a Hughes, 14 marzo 1924, RDS, 812.00/27187. moral maltrecha, los alzados, en plena retirada en los frentes principales, abrieron un nuevo capítulo en su lucha, presentándola ahora como de "defensa de la soberanía y la independencia de la patria". Adolfo de la Huerta, establecido en la nueva capital rebelde en Frontera, Tabasco, presentó a Obregón como un traidor que había ofrecido en venta la soberanía nacional "al más poderoso gobierno extranjero, a precio de barcos de guerra, aeroplanos, carabinas, proyectiles y dinero". Un delito de lesa patria fue denunciado en sus más duros términos en contra de los antiguos aliados sonorenses:

Cuando apenas comenzábamos a merecer el respeto y la consideración de los pueblos libres con el mantenimiento inquebrantable de una política digna y doblemente nacionalista, Obregón traiciona a su patria y traiciona a su raza, implorando, con ademán humillante y cínico, y obteniendo ayuda de un gobierno extranjero para perpetuarse en el poder y para iniciar con Plutarco Elías Calles una era de atentados y crímenes sin nombre. ${ }^{79}$

No importa que Obregón adquiera cañones de gobiernos extranjeros para derramar sangre de mexicanos... No importa que Obregón alquile pilotos norteamericanos para que desde sus aviones asesinen ancianos, mujeres y niños...Todos los que anhelen un porvenir de libertad para sus hijos, empuñarán las armas contra los traidores,

rezaba la proclama en la que De la Huerta presentaba a Obregón y a Ca-

79 De la Huerta, Manifiesto, 20 febrero 1924, en ARPADH. 
lles como lacayos de Washington y de los intereses petroleros estadunidenses en México. ${ }^{80}$

La proclama que denunció la ayuda extranjera a Obregón dio la impresión generalizada de ser fuertemente antiestadunidense y de poder levantar sentimientos negativos hacia los estadunidenses en México. Fiel a su línea de no antagonizar demasiado con ellos, $\mathrm{e}$ incluso de atraerlos a su causa, De la Huerta precisó el contenido de su lla. mado en términos de condena a la "antipatriota" actitud de Obregón, pero también de respeto irrestricto a los derechos de los ciudadanos de Estados Unidos en México, en un telegrama circular a sus jefes militares, gobernadores y otras autoridades:

Gentilmente conmino a ustedes más que nunca a velar que todo tipo de garantías y protección sea dado a los extranjeros que se encuentran en territorio controlado por nuestro movimiento y a quienes puedan estar bajo la jurisdicción de ustedes, a fin de demostrar que,

${ }^{80}$ En términos semejantes se expresó el general Alvarado, en un manifiesto sin fecha titulado "Al esforzado ejército nacional revolucionario y a los habitantes todos de la República", dirigido a sus soldados en Colima, después de la pérdida y evacuación de Guadalajara el 11 de febrero de 1924. El citado general denunció severamente al presidente, afirmando que "él había empleado extranjeros como pilotos de sus aeroplanos para asesinar mexicanos en su propio suelo". Vicecónsul en Manzanillo Aguirre a Hughes, 15 febrero 1924, RDS, 812.00/27104. Al poco tiempo, el 23 de febrero, Alvarado saldría acompañado por el cónsul americano George A. Bucklin a Vancouver desde Acapulco en un barco holandés después de haber escapado de Manzanillo. Pangburn a Hughes, Acapulco, 23 febrero 1924, en RDS, 812.00/27044. ahora que nosotros demandamos respeto para nuestros propios derechos, nosotros respetamos los derechos de otros y que es nuestro propósito vivir en completa armonía con todas las razas y pueblos. Yo por lo tanto recomiendo de la manera más formal en esta ocasión, que ustedes hagan todo esfuerzo para que no exista causa de queja de parte de los extranjeros, quienes deben sentir que sus personas están enteramente seguras y que sus intereses están garantizados y que ellos están igualmente obligados a respetar nuestras leyes y autoridades. ${ }^{81}$

El telegrama tuvo "el efecto psicológico natural de cristalizar el sentimiento revolucionario en Yucatán en favor de De la Huerta", afirmaría el cónsul estadunidense $O$. Gaylord Marsh. Notó, asimismo, un "ligero" sentimiento de hostilidad contra Estados Unidos entre la "mejor gente" de la península, que no atinaba a entender cómo este país podía ayudar a forzar un regreso del socialismo carrillopuertista a Yucatán. El gobierno rebelde local, encabezado por el general Ricárdez Broca, utilizó por su parte el argumento de la ayuda a Obregón para volcar al pueblo contra él, lo que ocasionó resentimientos populares contra los estadunidenses y Estados Unidos. Pero el peligro mayor estaba en otra parte, en el caso de una victoria obregonista, circunstancia en la que "los americanos (sí) estarían en peligro". 82

${ }^{81}$ Citado en inglés en R. L. Rankin a Hughes, Frontera, Tabasco, 23 febrero 1924, RDS, 812.00 / 27075.

${ }_{82}$ Cónsul en Progreso O. Gaylord Marsh a Hughes, 27 febrero 1924, RDS, 812.00/27086. 
Cuando la suerte ya estaba echada, cuando la victoria obregonista era cuestión de unos días, De la Huerta hizo el último intento de congraciarse con Estados Unidos desde su refugio en Frontera, de donde partiría hacia su exilio, que duró doce años. En una conversación que tuvo con el cónsul Rankin, le expresó su voluntad y deseo personal de presentar hechos importantes relativos a la situación en México, al secretario Hughes, si era invitado a hacerlo. Sostuvo que con el apoyo moral de Estados Unidos, él podría ganar decisivamente en muy poco tiempo, pero que "respetaría y aceptaría el veredicto de Mr. Hughes después de una entrevista confidencial, hasta la renuncia al uso de las armas". ${ }^{3} 3$ La respuesta de Hughes a esta petición fue tajantemente negativa: "La posición de este gobierno respecto a la situación presente en México permanece como hasta ahora ha sido públicamente anunciada". ${ }^{84}$ De la Huerta abandonaría el 12 de marzo de 1924 el puerto de Frontera a bordo del Explorador para después transbordar al Tabasco con rumbo a Estados Unidos a fin de hacer gestiones directas en Washington, aprovechando las relaciones que había logrado construir cuando estuvo en la capital norteamericana. ${ }^{85}$ Ante los rumores de que De

83 Rankin a Hughes, 10 marzo 1924, RDS, 812.00/27098.

${ }_{84}^{4}$ Hughes a Rankin, 12 marzo 1924, RDS, $812.00 / 27098$.

85 Los detalles de la salida de De la Huerta de Frontera se encuentran en Guzmán, Memorias, op. cit., pp. 267-272; Rankin a Hughes, 12 marzo 1924, RDS, 812.00/27108; cónsul Marsh a Hughes, 27 marzo 1924, RDS, 812.00/27153. la Huerta había huido a Estados Unidos, Associated Press informó que el jefe rebelde se encontraba todavía en Frontera, de donde recibió su mensaje: "He sido informado que los enemigos de la revolución están intentando hacer que los periódicos de Estados Unidos crean que yo he abandonado la república y soy un fugitivo en camino a algún país extranjero. Nada es más erróneo. Estoy al frente del comando supremo de la revolución [...] Nuestras tropas son muy entusiastas y no se consideran triunfantes hasta que sean derrocados los traidores". ${ }^{86}$ Don Adolfo no logró su propósito y dio inicio a su larga estancia en Estados Unidos. Zubarán Capmany, quien se mantuvo buscando infructuosamente llamar la atención de la Casa Blanca para un cambio de políticas, resumiría así sus frustraciones y esperanzas con respecto al futuro de su movimiento:

La actitud del gobierno de este país [EU] para el gobierno de Obregón, ha hecho fracasar todos nuestros esfuerzos para encontrar ayuda financiera, así como para modificar la severidad con que proceden las autoridades mexicanas contra los agentes revolucionarios. Los elementos mejor dispuestos han aplazado su ayuda, que dicen estar dispuestos a dar, cuando la actitud del gobierno americano cambie, y están seguros de que este cambio se realizará. El Departamento de Estado ha cerrado sus puertas a toda información mexicana que no le llegue por conducto de la Embajada de nuestro país. Es decir, el Departamento de Estado, cuando me-

${ }^{86}$ The Sun, 14 marzo 1924; Rankin a Hughes, 18 marzo 1924, RDS, 812.00/27130. 
nos en política mexicana, no quiere escuchar más que la voz de Obregón. ${ }^{87}$

El apoyo norteamericano a Obregón fue cesando de manera paulatina, en la medida en que la rebelión delahuertista se fue extinguiendo. La historia se puso del lado de la obsesión obregonista de estar en buenos términos con Washington, dado su convencimiento de que su régimen no sobreviviria sin el respaldo de los intereses públicos y privados de Estados Unidos. La ayuda que recibió fue el corolario final de un largo esfuerzo emprendido por el gobierno mexicano, en una competencia por recursos cuya decisión quedó en última instancia al arbitrio del presidente Coolidge. En rigor, las dos partes en conflicto fueron medidas con la misma vara: su disposición a avenirse a los dictados estadunidenses. Durante su presidencia provisional De la Huerta había dado muestras sobradas de rechazo a los condicionamientos resumidos en la expresión Tratado Previo, de larga historia. En su política hacia Estados Unidos, don Adolfo buscó la normalización de las relaciones de México explorando primero caminos diferentes al logro del reconocimiento de su gobierno, tal y como lo atestiguó la misión de don Fernando Iglesias Calderón, y luego, aceptando la posibilidad de reconocimiento, pero de manera incondicional. Esta línea de conducta fue seguida por De la Huerta en sus nuevas funciones como secretario de Hacienda, ahora a través de arreglos financieros y diplomáticos,

${ }^{87}$ Zubarán Capmany al licenciado Miguel Palacios Macedo, 22 mayo 1924, en APM. pero sin compromisos contractuales. No es de soprender, entonces, que Estados Unidos hubiera visto con buenos ojos la actitud de Obregón en las negociaciones de Bucareli, cuyos frutos vinieron a ser equivalentes al Tratado Previo, o si se quiere, el Tratado Previo disfrazado. No hay motivo alguno para suponer lo contrario, a pesar de los barriles de tinta gastados por los panegiristas oficiales para matener limpia la imagen de su jefe. En suma: había buenas razones para apoyar a Obregón como había buenas razones para rechazar a De la Huerta.

Con su intervención en los asuntos políticos mexicanos, el gobierno estadunidense en turno lanzó una iniciativa militar sin precedentes en nuestro país. La Casa Blanca violó su propia palabra -o al menos la palabra de Harding- de que no alentaría los conflictos armados en ninguna parte del mundo. No vaciló en respaldar al que consideraba el mal menor para sus intereses y en apagar así las inquietudes nacionalistas al sur de la frontera. Con Plutarco Elías Calles en la presidencia después de la caída delahuertista, Estados Unidos se creyó con derechos capitales para recibir de los mexicanos el suministro de hidrocarburos como un "pago justo" por su cooperación en la guerra civil, pero se equivocó. El asunto de la propiedad del subsuelo y la explotación de los hidrocarburos volvió a prenderse cuando Calles retomó las políticas de sus antecesores Carranza y De la Huerta, y con ello se reanudaron las tensiones entre los dos países, mismas que concluirian en forma definitiva hasta las vísperas de la segunda guerra mundial. 


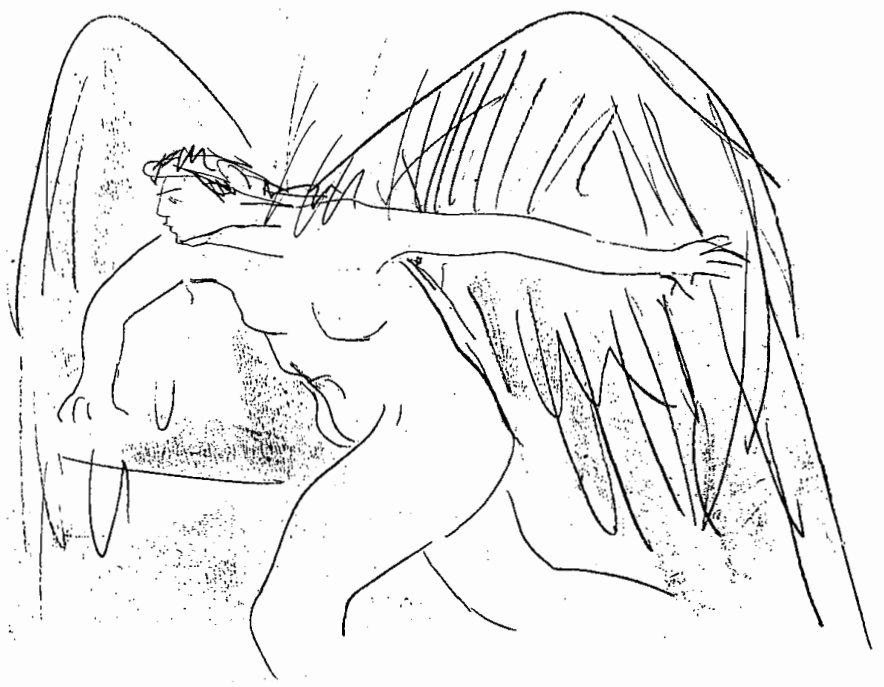

\section{BIBLIOGRAFIA CITADA}

\section{Archivos}

-U. S., 'The National Archives, Department of State, Records of the Departament of State Relating to Internal Affairs of Mexico, 1910-1929, Record Group 59 (RDS), Washington, D. C., 1959.

-Archivo de Recortes Periodísticos de don Adolfo de la Huerta (ARPDLH).

-Archivo del licenciado Miguel Palacios Macedo (APM).

\section{Documentos oficiales}

-Obregón, Álvaro, "Informe de 1921" en Informes rendidos por el C. Gral. Álvaro Obregón, presidente constitucional de los Estados Unidos Mexicanos ante el $\mathrm{H}$. Congreso de la Unión durante el periodo de 1921 a 1924, y Contestaciones de los C. presidentes del citado Congreso en el mismo periodo, México, Talleres linotipogräficos del "Diario Oficial", 1924.

-Secretaría de Relaciones Exteriores(SRE), La cuestión internacional mexicanoamericana durante el gobierno del Gral. don Álvaro Obregón, México, Secretaría de Relaciones Exteriores, 1926.

\section{Libros}

-Andrews, Gregg, Shoulder to shoulder?: The American Federation of Labor, the United States and the Mexican Revolution 1910-1924, Berkeley, University of California Press, 1991.

-Álvarez del Castillo, Juan Manuel, $M e$ morias, Guadalajara, Instituto Tecnológico de la Universidad de Guadalajara, 1960.

-Arriola, Enrique, La rebelión delahuertista, Secretaría de Educación Públi- 
ca/Martín Casillas, México, XII Memoria y Olvido, Imágenes de México, 1983.

-Dillon, E. J. Dr., Mexico on the verge,

G. Hutchinson \& Co., Londres (s. f.).

-Dulles, John W. F., Ayer en México, una crónica de la revolución mexicana, Fondo de Cultura Económica, México, 1977.

-Freeman-Smith, Robert, Los Estados Unidos y el nacionalismo revolucionario en México 1916-1932, Editorial Extemporáneos, México, 1973.

-Gill, Mario, Nuestros buenos vecinos, Editorial Azteca, México, 1959.

-Gómez Robledo, Antonio, Los Convenios de Bucareli ante el Derecho Internacional, Editorial Fábula, México, 1939.

-Guzmán Esparza, Roberto, Memorias de don Adolfo de la Huerta según su propio dictado, 2a. ed., Ediciones Guzmán, México, 1958.

-Martínez (Rip-Rip), Rafael, iSálvese el que pueda!, los días de la rebelión delahuertista, regalo de El Gráfico a sus lectores, 1931.

-Monroy Durán, Luis y Gonzalo Bautista, El último caudillo, José S. Rodríguez, Mérida, 1924.

-Neuchterlein, Donald E., Los intereses nacionales de los Estados Unidos en un mundo cambiante, Editorial Roble, México, 1975.

-Prieto Laurens, Jorge, Cincuenta años de política mexicana: memorias políti- cas, Editora Mexicana de Periódicos, Libros y Revistas, México, 1968.

-Ruiz, Ramón Eduardo, La gran rebelión 1905/1924, Ediciones Era, México, 1984.

-Trujillo, Rafael, Adolfo de la Huerta y los Tratados de Bucareli, $2^{\mathrm{a}}$ ed., Librería de Manuel Porrúa, México, 1966.

-Valadés, José, La revolución mexicana, vol. VII, Manuel Quesada Brandi Editor, Cuernavaca, 1967.

\section{Entrevistas}

-Embajador don Gilberto Bosques. México, D. F. , 11 de octubre de 1994.

-Ingeniero Arturo de la Huerta. Guaymas, Son. , 22 de octubre de 1994.

\section{Periódicos}

-Excélsior (México).

-The Evening World (Nueva York).

-The Journal of Commerce (Nueva York).

-The New York Herald (Nueva York).

-The New York Times (Nueva York).

-The Sun (Baltimore).

-The Tribune (Nueva York).

-The Tribune's Washington (Washington).

-The World (Nueva York). 


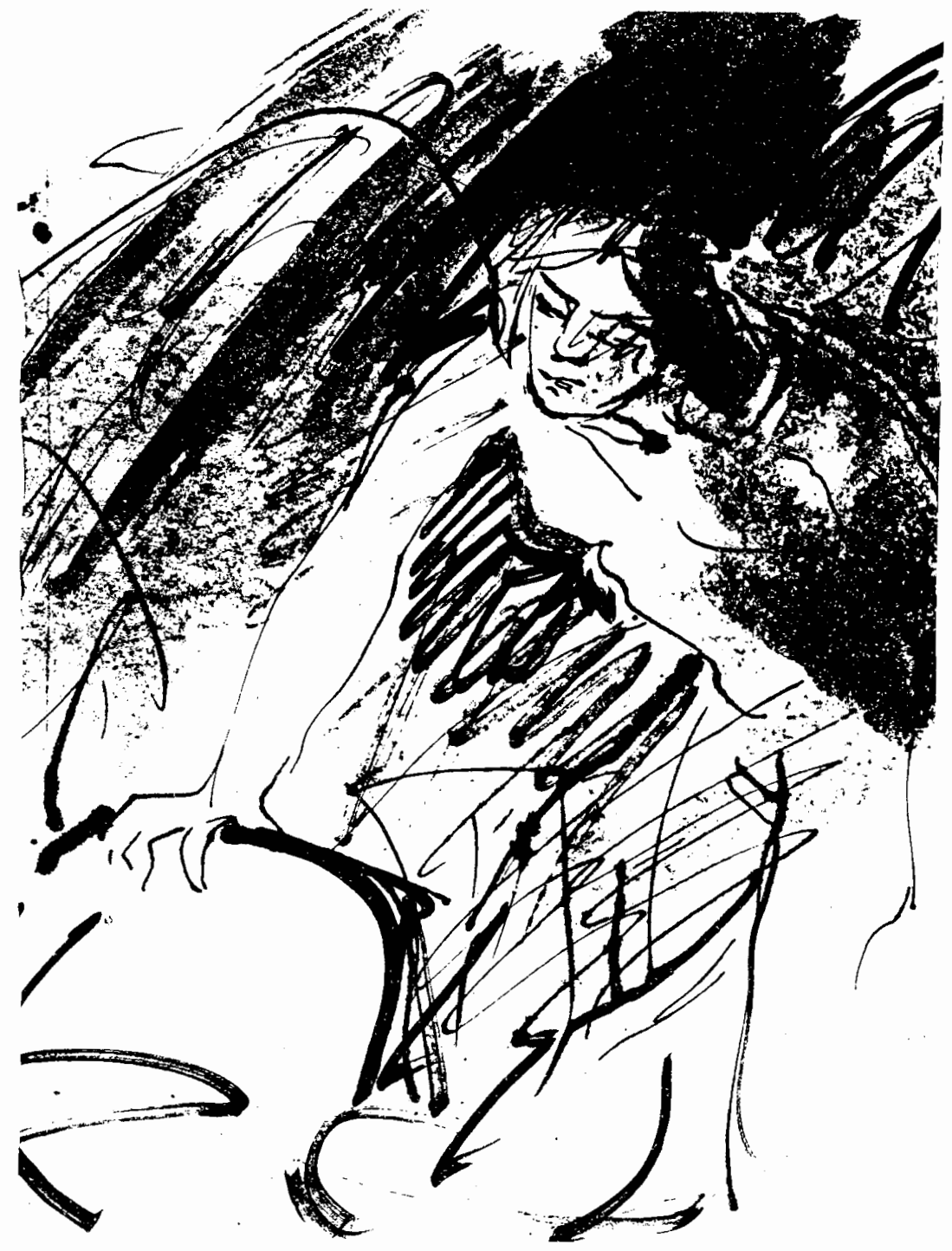

